\section{A clinical trial of endoscopic vs external dacryocysto- rhinostomy for partial nasolacrimal duct obstruction}

FH Zaidi', S Symanski',2 and JM Olver ${ }^{1}$

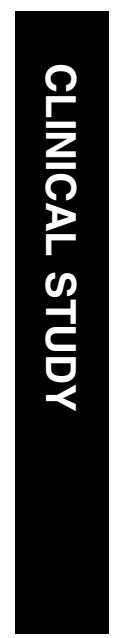

EES-DCR patients were all blocked on syringing. Statistically, EES-DCR does not achieve the same success rate as ext-DCR in this study $(P=0.09$, two-tailed Fisher's exact test, 0.045 one-tailed).

Conclusions Both endoscopic and external DCRs provide satisfactory outcomes in acquired partial NDO. The success rate is nevertheless higher in ext-DCR compared with EES-DCR.

Eye (2011) 25, 1219-1224; doi:10.1038/eye.2011.77; published online 22 July 2011

Keywords: external; endoscopic; endoscope; DCR; epiphora

\section{Introduction}

It is thought that partial nasolacrimal duct obstructions (NDOs) are associated with generally unpredictable surgical outcomes as compared with total blocks when using external dacryocystorhinostomy (ext-DCR) and silicone tube intubation. ${ }^{1-5}$ In the scientific literature, there are large gaps in our understanding of what benefit endoscopic DCR (EES-DCR) offers in partial NDO from clinical studies as opposed to anecdotal evidence, as summarised in Table $1 .^{3-5}$ The current study addresses two significant deficiencies in the evidence base. First, no prospective study had hitherto looked at the outcome of EES-DCR in the treatment of partial obstruction of the nasolacrimal system. This is a clinically important subgroup of patients who, as symptoms are not as severe as total obstruction, can be less willing to undergo ext-DCR and may be more likely to consider the advantages that EES-DCR offers. ${ }^{7,8}$ Second, this
${ }^{1}$ Department of

Ophthalmology, Charing Cross and Hammersmith Hospitals, London, UK

${ }^{2}$ Taub Eye Center, Chicago, IL, USA

Correspondence: FH Zaidi, Department of Ophthalmology, St Mary's, the Western Eye, Charing Cross and Hammersmith Hospitals, Fulham Palace Road, London W6 8RF, UK Tel: + 4407958030861 ; Fax: + 4402088461234 .

E-mail: fhz12@hotmail.com

Received: 23 July 2009 Accepted in revised form: 24 January 2011 Published online: 22 July 2011

Presented in part as a podium presentation at the European Society of Ophthalmic Plastic and Reconstructive Surgery (ESOPRS) Annual Meeting, Santiago de Compostela, Spain, 2001. 
Table 1 Existing studies in the literature that have studied 'functional' nasolacrimal duct obstruction

\begin{tabular}{|c|c|c|c|}
\hline Paper & Study type & External DCR (\%) & Endoscopic DCR (\%) \\
\hline Sahlin and Rose ${ }^{3}$ & Retrospective & $>50$ & No data \\
\hline $\mathrm{O}^{\prime}$ Donnell and Shah ${ }^{4}$ & Retrospective & 94 & No data \\
\hline Delaney and Khooshabeh ${ }^{5}$ & Retrospective & 70 & No data \\
\hline Brewis et $a l^{6}$ & Retrospective & No data & 78 (65\% complete cure) \\
\hline Current study & Prospective & 100 & 86 \\
\hline
\end{tabular}

Percentage success from surgery is shown. Outcome criteria have varied. These show that the current study fills two important gaps - it provides the first prospective data from any study on outcomes of endoscopic DCR in partial nasolacrimal duct obstruction; second, in addition, it provides the first prospective data for both types of operation. Sahlin and Rose's seminal work identified partial NDO using different inclusion criteria, longer follow-up, and included more complex cases from Moorfields Eye Hospital, hence the different outcomes. ${ }^{3}$ Brewis et al gave a caveat that it was not possible to reliably distinguish partial NDO from pump failure in cases of 'functional' NDO. ${ }^{6}$ The prospective work by Wormald and Tsirbas they cited did not isolate patients with partial NDO (see Discussion).

study also provides prospective data on the outcome of ext-DCR in this group, which had hitherto been lacking, and is important because the retrospective studies performed thus far have produced conflicting outcome data. The aim of this prospective study was to determine whether EES-DCR is effective in relieving the epiphora in patients with partial NDO. The results are compared with a similar patient group undergoing ext-DCR.

\section{Materials and methods}

The study was designed prospectively as a nonrandomised comparative clinical trial to investigate the outcome of EES-DCR vs ext-DCR for acquired (noncongenital) partial NDO.

Overall, 46 adults patients were identified from the Sub-specialist Oculoplastic and Lacrimal Service who fulfilled the criteria. Patients who had an acquired watering eye in the presence of patent nasolacrimal syringing, often accompanied by regurgitation of saline, were included. All patients had confirmation of nasolacrimal duct functional stenosis made by nuclear lacrimal scintigraphy or delayed emptying on late-erect dacryocystography views and not only on the basis of symptoms or findings from syringing. Exclusion criteria included patients with hypersecretion from ocular surface disease, epiphora from lid laxity or malposition, facial nerve weakness, canalicular or punctal stenosis, or obstruction identified on probing, and those with a history of previous nasolacrimal surgery, trauma, tumour or clinically suspected tumour, and granulomatous disease. All patients were recruited following informed consent. None of the original 46 patients were eliminated from the study, and no patient withdrew from the study.

There were 21 male and 25 female patients. The mean age was 62 years (range 26-94).

A standard pre-operative assessment sheet, pre-operative and post-operative proforma was used. Patients selected themselves which group they wished to enter, EES-DCR or ext-DCR, and with counselling, which included information about the risk of facial scar, and the slightly higher success rate generally reported with ext-DCR. All patients had pre-operative nasoendoscopic evaluation to identify potentially significant intranasal pathology and those with nasal septal deviation in whom a septoplasty might be required.9,10 There were no patients with significant nasal pathology or septal deviation that could impede surgery.

EES-DCR was performed under local anaesthetic as a day-case, jointly by a consultant ophthalmologist assisted by a consultant otolaryngologist if needed, using standard functional endoscopic sinus surgery (FESS) instruments and a $4 \mathrm{~mm} 0^{\circ}$ rigid Hopkins nasal endoscope. A fibreoptic light pipe was inserted into the lacrimal sac via either the upper or lower canaliculus. The resultant transillumination of the nasal cavity was visualised endonasally. The transilluminated nasal mucoperiosteum over the light pipe was incised with a Freer's periosteal elevator and removed using Blakesley forceps. The rhinostomy was made using FESS instruments and occasionally a small osteotome. The lacrimal bone was excised with limited maxillary bone removal. A standard keratome $(2.8 \mathrm{~mm})$ was used to open the lower part of the lacrimal sac and upper nasolacrimal duct vertically. O'Donoghue silicone tubes were inserted and knotted.

Standard ext-DCR surgery was performed by the consultant ophthalmologist under local anaesthetic as a day-case. A 1.2-cm vertical skin incision was made at $1 \mathrm{~cm}$ nasal to the medial canthus, avoiding the angular vessels. The periosteum at the anterior lacrimal crest was incised using a Traquair's periosteal elevator and the lacrimal fossa entered. The lacrimal and maxilla bones were removed with Kerrison rongeurs to create a large rhinostomy. Posterior and anterior mucosal flaps were made and all patients were intubated with $\mathrm{O}^{\prime}$ Donoghue tubes, followed by standard skin closure. ${ }^{11}$

Patients were reviewed at approximately 3 months after surgery for removal of tubes and a minimum of 6 months after surgery for final assessment. 


\section{Main outcome measures}

Outcome was assessed at 6 months after surgery, being 3 months after removal of O'Donoghue tubes. Subjective success was based on patient's symptoms, objective success on patency with syringing, and the presence of a functioning rhinostomy, evaluated using the functional endoscopic dye test (FEDT). Subjective success was based on the degree of epiphora at 6 months, which the patient graded as completely resolved, markedly reduced, minimally reduced or unchanged, or worse. Objective assessment was made by the examining ophthalmologist with lacrimal syringing and rigid nasoendoscopy to assess the FEDT and appearance of the rhinostomy. A functioning rhinostomy had a positive FEDT in which a drop of $2 \%$ fluorescein instilled in the conjunctival fornix was visualised emerging from the rhinostomy at 2-10s later.

\section{Results}

\section{Subjective reporting of symptoms is tabulated}

Patients who had complete resolution or markedly reduced symptoms of epiphora were regarded as successful (Table 2).

\section{Statistical analysis}

The success rates for EES-DCR and ext-DCR group were compared using the Fisher's exact test, which produced a $P$-value of 0.09 (two-tailed) and 0.045 (one-tailed).

\section{Complications}

There were no pre- or post-operative complications of haemorrhage, orbital air emphysema, or infection.

\section{Outcome of EES-DCR}

Success rate for EES-DCR was 18/21 (86\%). In total 11 patients had marked reduction (53\%) and 7 had complete resolution of symptoms (33\%). Out of 18 patients 17 (94\%) EES-DCR patients with subjective success had a positive FEDT. The remaining patient had a negative FEDT with a small peri-rhinostomy granuloma. The patients with marked reduction in epiphora had some mild regurgitation on syringing, whereas those who had full resolution were syringe patent. The three failed EESDCR patients (14\%) were all blocked on syringing, two with scarred rhinostomies and one with a large granuloma.

\section{Outcome of external DCR}

Success rate for ext-DCR was 25/25 (100\%). Nine patients had marked reduction (36\%) and 16 had complete
Table 2 Subjective outcome following endoscopic endonasal surgical DCR compared with external DCR, assessed 6 months after surgery

\begin{tabular}{lcc}
\hline & $\begin{array}{c}\text { EES-DCR } \\
\mathrm{n}=21(\%)\end{array}$ & $\begin{array}{c}\text { Ext-DCR } \\
\mathrm{n}=25(\%)\end{array}$ \\
\hline Symptoms of epiphora & & \\
Completely resolved $^{(\mathrm{i})}$ & $7(33)$ & $16(64)$ \\
Markedly reduced $^{(i)}$ & $11(53)$ & $9(36)$ \\
Unchanged or minimally reduced $^{\text {Worse }}$ & $3(14)$ & $0(0)$ \\
& $0(0)$ & $0(0)$ \\
\hline
\end{tabular}

Abbreviations: EES-DCR, endoscopic endonasal surgical dacryocystorhinostomy; Ext-DCR, external approach dacryocystorhinostomy.

Fisher's exact test comparing (i) + (ii) between each group $=0.09$ (two-tailed) and 0.045 (one-tailed).

resolution of symptoms (64\%). All patients had a positive FEDT.

The patients with marked reduction of epiphora also had some mild regurgitation on syringing, whereas those with full resolution of symptoms were all syringe patent. Neither patients had a scarred rhinostomy nor a granuloma.

\section{Discussion}

Hitherto there have been important gaps from clinical studies in our understanding of what benefit EES-DCR offers in partial NDO, excepting anecdotal evidence, as summarised in Table $1 .^{3-5}$ Patients with partial NDO represent one important subgroup of patients with what some authors have called 'functional' epiphora-a watering eye in the presence of patent nasolacrimal syringing in the absence of hypersecretion. In the literature the term is used to encompass three major groups: (1) reflex tearing, (2) pump failure and eyelid laxity, (3) partial outflow obstruction, which may be upper (punctal and canalicular stenosis) or lower (nasolacrimal duct stenosis), the latter partial obstruction also being called by some authors 'functional NDO' (FNDO). ${ }^{1}$ Partial stenoses of the nasolacrimal duct progress in an unknown proportion of cases to complete NDO. ${ }^{1}$ Partial NDO accounts for a significant number of patients attending lacrimal clinics, though sufferers may be less likely to be offered ext-DCR surgery in many units as symptoms are purely flow symptoms as opposed to flow (tearing) and volume (mucous/purulent discharge) symptoms - though these symptoms are often still very marked and cause disabling epiphora., 3 Patients with partial NDO typically have watering eyes with variable severity of symptoms unlike those typically associated with complete obstruction - usually tears build up and then discharge onto the cheek rather than watering all the time. ${ }^{7}$ On examination, this group of patients usually 
display slight regurgitation of saline on nasolacrimal syringing. ${ }^{7}$ A diagrammatic proforma of the type devised by Malhotra et $a l^{12}$ was used to document obstruction in the nasolacrimal duct (this study did not include canalicular constrictions). Confirmation using radiological imaging is often advocated including by the American Academy of Ophthalmology, as used in the current study. ${ }^{1,13}$ Lacrimal scintigraphy is slightly more sensitive than dacryocystography. ${ }^{14}$ Some authors advocate a dacryocystogram initially and scintigraphy later if the former is normal so as to avoid false negatives; however, increasing scintigaphy on its own is being performed as the only form of imaging for these patients. ${ }^{7,14}$

It is only recently that outcomes from subtotal NDO have been studied distinctly to total obstructions, and they seem to be associated with generally worse surgical outcomes to total blocks (Table 1)..$^{3-5,15,6}$ The first study to highlight this interesting subgroup of patients with partial blocks was a retrospective review of 37 patients with 'functional block' treated with external DCR and estimated a success rate of at least $50 \%$, though criteria for success were different to this study. ${ }^{3}$ A second study, carried out using the same criteria for success as we have in this study, treated 51 patients with patent lacrimal drainage systems and epiphora by ext-DCR and found a success rate of $94 \% .{ }^{4}$ A third study examined the success rates of ext-DCR for patients with acquired partial nasolacrimal obstruction, but the inclusion criteria included those with proximal or canalicular stenosis as well as post-sac nasolacrimal duct stenosis. ${ }^{5}$ A significantly lower success for patients treated with ext-DCR for pre-sac compared with post-sac stenosis was found. We did not include any patients with significant canalicular stenosis. Recently, a fourth study attempted to investigate the outcome of EES-DCR in epiphora not associated with total occlusion of the NDO. ${ }^{6}$ In contrast, there have been innumerable studies on total obstruction. ${ }^{15-28}$ Brewis et al ${ }^{6}$ felt it was not possible to reliably distinguish partial NDO from pump failure. Prospective data by Wormald and Tsirbas ${ }^{29}$ did not isolate patients with partial NDO focussing on imaging. Sahlin and Rose's paper from 2001 is the seminal work in this field being the first to clearly identify partial NDO - owing to different inclusion criteria, longer follow-up and more complex cases from Moorfields Eye Hospital the outcome rate is different to the current study. ${ }^{3}$

The results of the current study suggest that EES-DCR is an acceptable surgical option for the management of partial NDO, though the success rate is nevertheless higher in ext-DCR compared with EES-DCR. The subjective results agreed strongly with objective findings. On the basis of subjective criteria, this trial shows a successful outcome of $86 \%$ with EES-DCR and $100 \%$ with
ext-DCR. Three patients with EES-DCR surgery had failed surgery - irrigation was blocked and the rhinostomy either scarred or occluded by a large granuloma. This represents either a progression of their disease or an iatrogenic obstruction.

External dacryocystorhinostomy is used in various forms to treat NDO for over 100 years. ${ }^{15,16}$ In comparison, EES-DCR is much more recent, ${ }^{17}$ interest in it being re-kindled because of advances in instrumentation, notably the introduction of the rigid nasoendoscope, FESS, and laser surgery. ${ }^{13,18-21}$ Ext-DCR is still regarded as the gold standard in terms of functional outcome. ${ }^{11,22}$ For example, a large study of patients with complete NDO by Dolman, ${ }^{22}$ compared the outcome of 153 ext-DCR (90.2\% success) with 201 EES-DCR $(89.1 \%$ success). There was no statistically significant difference between these two approaches. ${ }^{22}$ Several surgeons have found distinct advantages of the endonasal route, that is, the surgery was faster and is preferred by certain patients. ${ }^{11,22}$

EES-DCR has advantages, which are of special relevance to many patients with partial NDO, who owing to troublesome, but often inconstant, symptoms may be less likely to be offered or to accept ext-DCR. ${ }^{1,7}$ These include the avoidance of a skin incision, which is of cosmetic importance to certain patient groups, such as young patients, ${ }^{23,24}$ to those with dark skin prone to keloid formation, ${ }^{24}$ as well as patients with a flat nasal bridge. ${ }^{24}$ In addition, EES-DCR avoids damage to the medial canthal tendon and the potential of a medial canthal deformity. Surgery is more likely to be performed as a day-case, but the results in the literature tend not to be as good as ext-DCR, presumably as a smaller rhinostomy has traditionally been created by most surgeons who perform the procedure, though this practice varies between units. ${ }^{13,20,21,23-27}$ The use of adjuvant pre-operative Mitomycin $\mathrm{C}$ may improve the success rates for EES-DCR. In the current study, approximately 70\% EES-DCR operations were planned as day-cases under local anaesthesia, but in practice, no patients required prolonged inpatient admission after surgery. Non-EES-DCR can be used in developing countries where perhaps the nasal endoscope and FESS instruments are not readily available or the other nonDCR procedures can be tried first. Mechanical EES-DCR is a promising development and by creating a large rhinostomy and preserving the lacrimal and nasal mucosa preserves the main advantages of ext-DCR. ${ }^{21}$

In summary, the current study provides the first results from a prospective study for the role of DCR in partial NDO. In addition, it provides the first substantial data on outcomes using EES-DCR in this subgroup of cases. Hitherto this study, no prospective data existed showing good outcomes for treatment of partial NDO using DCR, 
and hence other treatment modalities often continue to be tried in addition to DCR. The success rate achieved with both EES-DCR and ext-DCR in this study are hence also worth comparing with the results of other treatment modalities. These include bicanalicular nasolacrimal duct intubation, and balloon dacryoplasty with or without intubation. $^{2}$ The most recent work shows that the results for silicone tube intubation in partial NDO are disappointing, with about a 50\% failure and overall about $20-25 \%$ of patients opting for subsequent ext-DCR. The current study shows outcomes for both EES-DCR and ext-DCR have higher success rates than these alternative procedures. Further, they are more likely to be effective in the long term in partial NDO as the condition is frequently progressive ${ }^{28}$ whereas in DCR the rhinostomy is made above the stenosis. Redosurgery, by either EES-DCR or ext-DCR is relatively straightforward. In conclusion, EES-DCR has a high success rate, as defined by complete or markedly reduced watering, together with some advantages over ext-DCR, such as there being no surgical manipulation of the medial canthal tendon and features that certain patients might find attractive such as the absence of a visible scar. However, statistically EES-DCR probably does not achieve the same success rate as ext-DCR in this study. More prospective case numbers may clarify the situation in future studies.

\section{Summary}

What was known before

- There is no data for outcomes of endoscopic DCR in partial nasolacrimal duct obstruction.

- Outcomes from external DCR in this same subgroup of patients are variable depending on the study, which all comprise retrospective studies.

- The condition is of clinical importance.

What this study adds

- Provides the first prospective data on the outcomes of endoscopic DCR in this group of patients. The outcomes are very good.

- Provides prospective data on the outcomes of external DCR in this group of patients. The results are better than retrospective studies suggested.

\section{Conflict of interest}

The authors declare no conflict of interest.

\section{References}

1 Chung YA, Yoo IeR, Oum JS, Kim SH, Sohn HS, Chung SK The clinical value of dacryoscintigraphy in the selection of surgical approach for patients with functional lacrimal duct obstruction. Ann Nucl Med 2005; 19: 479-483.
2 Bleyen I, Paridaens AD. Bicanalicular silicone intubation in acquired partial nasolacrimal duct obstruction. Bull Soc Belge Ophtalmol 2008; 309-310: 23-26.

3 Sahlin S, Rose GE. Lacrimal drainage capacity and symptomatic improvement after dacryocystorhinostomy in adults presenting with patent lacrimal drainage systems. Orbit 2001; 20: 173-179.

4 O'Donnell B, Shah R. Dacryocystorhinostomy for epiphora in the presence of a patent lacrimal system. Clin Experiment Ophthalmol 2001; 29: 27-29.

5 Delaney YM, Khooshabeh R. External dacryocystorhinostomy for the treatment of acquired partial nasolacrimal obstruction in adults. Br J Ophthalmol 2002; 86: 533-535.

6 Brewis C, Yung M, Merkonidis C, Hardman-Lea S. Endoscopic dacryocystorhinostomy in functional lacrimal obstruction. J Laryngol Otol 2007; 27: 1-3.

7 Cheung LM, Francis IC, Stapleton F, Wilcsek G. Symptom assessment in patients with functional and primary acquired nasolacrimal duct obstruction before and after successful dacryocystorhinostomy surgery: a prospective study. Br J Ophthalmol 2007; 91: 1671-1674.

8 Olver JM. Adult lacrimal surgery. In: Olver JM (ed.). Colour Atlas of Lacrimal Surgery. Butterworth-Heinemann: Oxford, 2002; Chap. 5.

9 Olver JM, Minasian M. Nasal endoscopy for ophthalmologists. CME J Ophthalmol 1998; 2: 73-77.

10 Minasian M, Olver JM. The value of nasal endoscopy after dacryocystorhinostomy. Orbit 1999; 18: 167-176.

11 Olver JM. The success rates for endonasal dacryocystorhinostomy. Br J Ophthalmol 2003; 87(11): 1431.

12 Malhotra R, Olver JM. Diagrammatic representation of lacrimal disease. Eye 2000; 14: 358-363.

13 Woog JJ, Kennedy RH, Custer PL, Kaltreider SA, Meyer DR, Camara JG. Endonasal dacryocystorhinostomy: a report by the American Academy of Ophthalmology. Ophthalmology 2001; 108: 2369-2377.

14 Wearne MJ, Pitts J, Frank J, Rose GE. Comparison of dacryocystography and lacrimal scintigraphy in the diagnosis of functional nasolacrimal duct obstruction. Br J Ophthalmol 1999; 83: 1032-1035.

15 Toti A. Nuovo metodo conservatore di cura radicale delle suppurazioni croniche del sacco lacrimale (Dacriocistorinostomia). L Clin Mod 1904; 10: 385-387.

16 Caldwell GW. Two new operations for obstruction of the nasal duct, with preservation of the canaliculi, and an incidental description of a new lacrymal probe. NY Med J 1893; 57: 581-582.

17 Jokinen K, Karja J. Endonasal dacryocystorhinostomy. Arch Otolaryngol 1974; 100: 41-44.

18 Massaro BM, Gonnering RS, Harris GJ. Endonasal laser dacryocystorhinostomy. a new approach to nasolacrimal duct obstruction. Arch Ophthalmol 1990; 108: 1172-1176.

19 Metson R, Woog JJ, Puliafito CA. Endoscopic laser dacryocystorhinostomy. Laryngoscope 1994; 104: 269-274.

20 Woog JJ, Metson R, Puliafito CA. Holmium:YAG endonasal laser dacryocystorhinostomy. Am J Ophthalmol 1993; 116: 1-10.

21 Tsirbas A, Wormald PJ. Mechanical endonasal dacryocystorhinostomy with mucosal flaps. Br J Ophthalmol 2003; 87: 43-47.

22 Dolman PJ. Comparison of external dacryocystorhinostomy with nonlaser endonasal dacryocystorhinostomy. Ophthalmology 2003; 110: 78-84. 
23 Hartikainen J, Antila J, Varpula M, Puukka P, Seppä H, Grénman R. Prospective randomized comparison of endonasal endoscopic dacryocystorhinostomy and external dacryocystorhinostomy. Laryngoscope 1998; 108: 1861-1866.

24 Duffy MT. Advances in lacrimal surgery. Curr Opin Ophthal 2000; 11: 352-356.

25 Gonnering RS, Lyon DB, Fisher JC. Endoscopic laser-assisted lacrimal surgery. Am J Ophthalmol 1991; 111: 152-157.

26 Sadiq SA, Hugkulstone CE, Jones NS, Downes RN. Endoscopic holmium:YAG laser dacryocystorhinostomy. Eye 1996; 10: 43-46.
27 Moore WM, Bentley CR, Olver JM. Functional and anatomic results after two types of endoscopic endonasal dacryocystorhinostomy: surgical and holmium laser. Ophthalmology 2002; 109: 1575-1582.

28 Bartley GB. Acquired lacrimal drainage obstruction: an etiologic classification system, case reports, and a review of the literature. Part 1. Ophthal Plast Reconstr Surg 1992; 8: 237-242.

29 Wormald PJ, Tsirbas A. Investigation and endoscopic treatment for functional and anatomical obstruction of the nasolacrimal duct system. Clin Otolaryngol Allied Sci 2004; 29(4): 352-356. 